IJPN: Genetics in palliative care: too much to ask?

\title{
Genetics in palliative care: too much to ask?
}

Chris Jacobs ${ }^{1}$, Stephanie White ${ }^{2}$, Jane Phillips ${ }^{3}$

1. Senior Lecturer, Genetic Counselling, University of Technology Sydney (UTS) Ultimo, NSW Australia

2. Associate Genetic Counsellor, Familial Cancer Service, Royal North Shore Hospital, Sydney, NSW Australia

3. Professor of Palliative Nursing, Director of IMPACCT, University of Technology Sydney (UTS) Ultimo, NSW Australia

Editorial: International Journal of Palliative Nursing

Conflict of interests: The authors declare no conflict of interests

Key words: Genetic/ genomic testing, palliative care, family history

\begin{abstract}
People with an inherited condition who receive palliative care may be missing out on the opportunity to store a DNA sample for future use by their families and offspring. A DNA sample from a family member affected with an inherited condition can help at-risk relatives to access accurate risk assessment and, where relevant, enhanced surveillance and risk reducing measures. As genetic and genomic testing becomes increasingly important in all aspects of health care, health professionals specializing in palliative care will be asked to communicate about family history risk and testing. This article highlights the importance of discussing genetics and genomics issues for people receiving palliative care, their families and the health professionals caring for them.
\end{abstract}


IJPN: Genetics in palliative care: too much to ask?

For the person dying from an inherited condition, palliative care may be the last opportunity to store a DNA sample for future use by their families and offspring so that they can accurately appraise their individual risk of developing the same condition. Banking a DNA sample for future use may enable family members to access an accurate risk assessment and make informed decisions about managing their own risk and the risk to their children, for example, engaging in appropriate screening or risk reducing surgery. Yet, despite the global recognition of the importance of genetics and genomics in healthcare, discussion of these issues is largely missing from the palliative care agenda (Morrow et al., 2018).

A large proportion of people receiving palliative care will have a diagnosis of cancer. Up to $10 \%$ of common cancers are due to a pathogenic variant (gene mutation) (Foulkes, 2008). Most inherited common cancers, such as breast and ovarian cancer and Lynch Syndrome are dominantly inherited, whereby each first-degree relative (child, sibling or parent) of an affected individual is at $50 \%$ risk of having inherited the pathogenic variant. In addition to cancer, there are other adult onset life-limiting conditions that are, or can be, due to a pathogenic variant, such as Huntington's disease, adult-onset autosomal dominant leukodystrophy and Cerebral Autosomal Dominant Arteriopathy with Subcortical Infarcts and Leukoencephalopathy (CADASIL). For children receiving palliative care, there is an even higher possibility of genetic involvement with up to $50 \%$ of expected childhood deaths being due to a pathogenic variant (Burton, 2003).

There is growing awareness of the importance of identifying individuals with inherited conditions early in their diagnosis, especially in the management of cancer where targeted treatment may be available. Genomic testing is increasingly relevant to all areas of medicine, with governments from over 14 countries, including the UK, Australia, the USA and parts of Europe, making substantial investments in the translation of genomic research into mainstream clinical practice (Stark et al, 2019). 
IJPN: Genetics in palliative care: too much to ask?

There are several reasons why families may be unaware of the possibility of an inherited condition close to the end of life. Older people and those diagnosed at a late stage of disease may be referred directly into palliative care, bypassing medical oncology. Family histories are dynamic and sometimes genetic testing may not be offered until several relatives have been diagnosed with a similar condition. Alternatively, people may have been offered testing at an earlier stage and declined, but change their minds as the focus of testing shifts from the individual to the family.

People who are eligible for genetic testing are frequently not identified from palliative care (Daniels et al., 2009, Quillin et al., 2010). Even when eligible individuals are identified, they are not always referred to specialist genetics services (Lanceley et al., 2012). There are many possible barriers to discussing genetic testing in palliative care, including lack of confidence and knowledge (Quillin et al., 2011), limited awareness of how to access genetics services (Metcalfe et al., 2009, Metcalfe et al., 2010, Dearing and Taverner, 2017), uncertainty about whose responsibility it is to raise the issue with eligible individuals and families (Metcalfe et al., 2009, Metcalfe et al., 2010) and concern about causing additional distress (Lillie et al., 2011). Yet, people receiving palliative care have expressed positive feelings about discussing genetic testing, such as reassurance, interest and a sense of altrusim (Abusamaan et al., 2018, Daniels et al., 2009, Lillie et al., 2011). Overcoming these barriers requires an in depth understanding of the attittudes, behaviours and knowledge of palliative care health professionals towards genetic testing and a evidence-based approach to changing practice.

Unless the issue is raised with individuals and families in the palliative care setting, those not at high risk may be concerned where they could be reassured. Alternatively, those at high risk may miss out on the opportunity to help their loved ones understand the cause of the condition, protect future generations and enable targeted treatment of relatives who may become ill in the future. As genetic and genomic testing becomes increasingly important in

Commented [CJ1]: Steph can you register the systematic review on PROSPERO before $31^{\text {st }}$ May and then we can reference it here and stake our claim? 
IJPN: Genetics in palliative care: too much to ask?

all aspects of health care, health professionals in all areas, including palliative care, will be asked to communicate about family history risk and testing.

\section{References}

Abusamaan MS, Quillin JM, Owodunni O et al (2018) The role of palliative medicine in assessing hereditary cancer risk Am J Hosp Palliat Care Jan 1(E pub)

Burton $\mathrm{H}$ (2003) Addressing genetics, delivering health: a strategy for advancing the dissemination and application of genetics knowledge through our health professions https://wellcome.ac.uk/sites/default/files/wtd003179_0.pdf (Accessed 19.09.18)

Daniels MS, Urbauer DL, Stanley JL et al (2009) Timing of BRCA1/BRCA2 genetic testing in women with ovarian cancer Genet Med 11(9):624-8

Dearing A, Taverner N (2017) Mainstreaming genetics in palliative care: barriers and suggestions for clinical genetic services J Community Genet 9(3):243-256

Foulkes WD (2008) Inherited susceptibility to common cancers New Engl J Med 359(200: 2143-2153

Lanceley A, Eagle Z, Ogden G et al (2012) Family history and women with ovarian cancer: is it asked and does it matter?An observational study Int J Gynecol Cancer 22(2):254-9

Lillie AK, Clifford C, Metcalfe A (2011) Caring for families with a family history of cancer: Why concerns about genetic predisposition are missing from the palliative agenda Palliat Med 25(2):117-24

Metcalfe A, Pumphrey R, Clifford C (2009) Children affected by genetic conditions in end-oflife care. Part 2: findings and discussion International Journal of Palliative Nursing 15(1):22-28

Metcalfe A, Pumphrey R, Clifford C (2010) Hospice nurses and genetics: implications for end-of-life care J Clin Nurs 19(1-2):192-207

Morrow A, Jacobs C, Best M et al (2018) Genetics in palliative oncology: a missing agenda? A review of the literature and future directions Support Care Cancer 26(3):721-730

Quillin J, Bodurtha J, Siminoff $L$ et al (2010) Exploring hereditary cancer among dying cancer patients-a cross-sectional study of hereditary risk and perceived awareness of DNA testing and banking J Genet Couns 19(5):497-525

Quillin J, Bodurtha J, Siminoff $L$ et al (2011) Physicians' current practices and opportunities for DNA banking of dying patients with cancer J Oncol Pract 7(3):183-187

Stark Z., Dolman L., Manolo TA. et al (2019) Integrating Genomics into Healthcare: A Global Responsibility. AJHG 104(1): 13-20 